\title{
Testing and Calibration of Temperature Gauges using Webcam based Non-Invasive Technique
}

\author{
Zainul Abdin Jaffery \\ Department of Electrical Engineering \\ Faculty of Engineering and Technology, \\ Jamia Millia Islamia, New Delhi, India
}

\author{
Ashwani Kumar Dubey \\ Department of Electrical Engineering \\ Faculty of Engineering and Technology, \\ Jamia Millia Islamia, New Delhi, India
}

\begin{abstract}
In this paper, a contact less testing and calibration system is developed for temperature gauges. The system captures the images of temperature gauge at a regular interval, detects the desired region of interest using algorithms and segments the needle for further processing. The segmented image properties are calculated and matched with the standard data to indentify the indicated value. The system is capable enough to generate alarm and emboss 'defective sample' on the gauge under test. In the field manufacturing, non invasive visual inspection systems are replacing the need of human inspector to prevent the inclusion of incorrect parts or to check the quality of goods.
\end{abstract}

\section{General Terms}

Calibration and Testing

\section{Keywords}

AVIS, Image Acquisition, NITCS, ROI, Threshold.

\section{INTRODUCTION}

In mass-production process, $100 \%$ quality achievements are always a line of demand for all finished products. To achieve this goal, automatic visual inspection systems(AVIS) [1]-[8] are found very much suitable because of its reliability, robustness, consistent performance, low running cost, flexibility in applications, user friendly, fast, high accuracy, mass production capability and hence reduction in the cost of the products, and low failure rate. It also helps in identifying functional and cosmetic defects. The use of visual inspection for finished product becomes a necessity to fulfill the industrial quality standards. It is now the adaptive ethical policy that products should not be shipped to customers if it is not gone through quality check and gives guaranty for defectfree. In fact, the human visual inspectors are best between 70$80 \%$ inspection levels but visual inspection system (VIS) enhances this level to $99.99 \%$ [5]-[11].

The prevalence of visual inspection applications is to hunt the decipher quality problems by using artificial intelligence techniques, model-based visual inspection techniques, and imperfection detection techniques. The main objective of these applications is to eradicate imperfect goods from the manufacturing process before additional value is added to the faulty product or before the faulty product is released to the consumer. Therefore, inspection systems are meant to monitor all manufacturing steps and report the defects rapidly.
The automatic visual inspection systems (AVIS) are noninvasive in nature hence risk of product damage during inspection is negligible. An Automated visual inspection is viable for the use of large part volumes, accurate measurements, and $100 \%$ inspection in hazardous location. It helps in yielding the greater customer satisfaction, lowering production costs and increasing market shares [12]-[15].

\section{PROPOSED VIS MODEL}

Initially, the visual inspection systems were applied in the manufacturing industries because there was a sturdy need to automate the manufacturing process and to monitor the final goods. In this process, the goods are checked for permitted tolerance bands of given standard, functional or superficial defects. Afterward the VIS are modified and made capable enough to sort the defective products from the process. In the beginning, human inspectors were employed in process and manufacturing industries to carry out the tasks of visual inspection. Now, the complete inspection scenario is changed and human inspectors are replaced by smart visual inspection systems with more accurate results and robust performance.

Initially, the visual inspection systems were applied in the manufacturing industries because there was a sturdy need to automate the manufacturing process and to monitor the final goods. In this process, the goods are checked for permitted tolerance bands of given standard, functional or superficial defects. Afterward the VIS are modified and made capable enough to sort the defective products from the process. In the beginning, human inspectors were employed in process and manufacturing industries to carry out the tasks of visual inspection. Now, the complete inspection scenario is changed and human inspectors are replaced by smart visual inspection systems with more accurate results and robust performance.

\subsection{Existing System}

Figure 1 represents the existing manual testing and calibration system which has to be replaced by the visual inspection system. Figure 2 (a) shows the gauge to be tested and Figure2 (b) represents the electrical equivalent diagram of gauge. The calibration is done by changing the resistance of variable resistance $\left(\mathrm{R}_{2}\right)$ as per the values mentioned in Table 1 for the particular temperature position. If the needle is found exactly overlapped with white line marked on the gauge for particular temperature when $\mathrm{R}_{2}$ is set accordingly then that position is marked as 'OK' otherwise 'NOT OK'. 


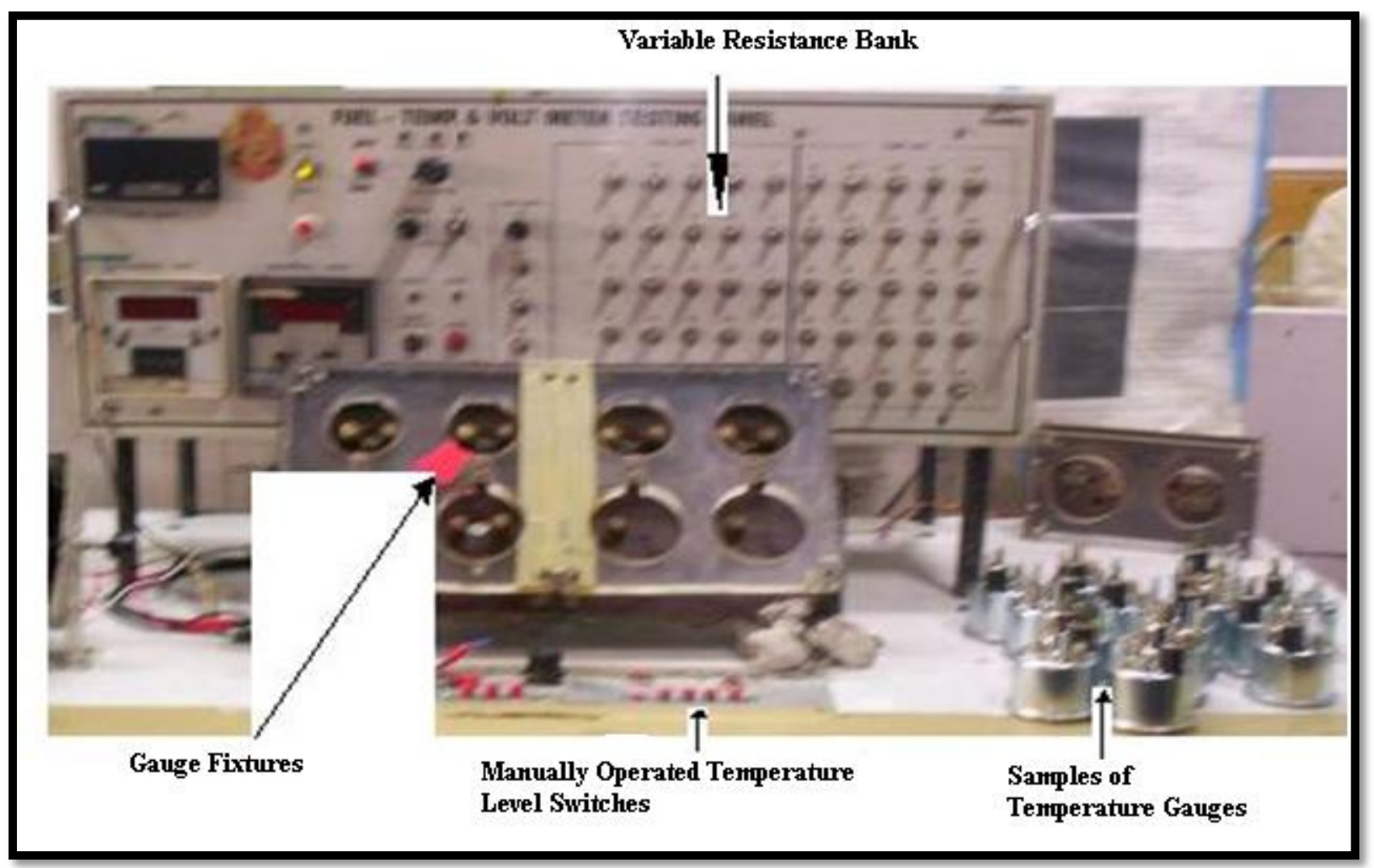

Fig1: Existing manual testing system

\subsection{Gauge Model and System}

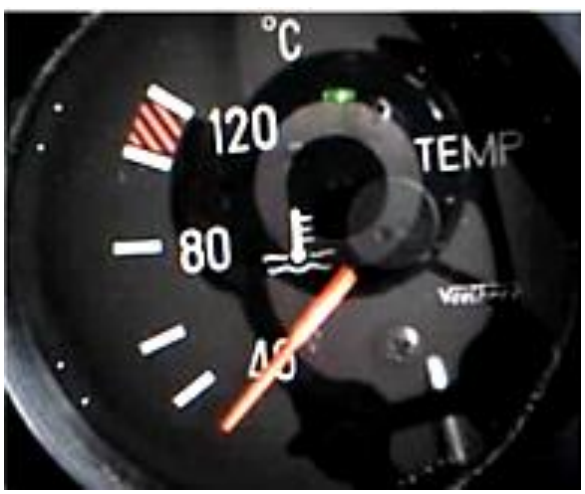

(a)

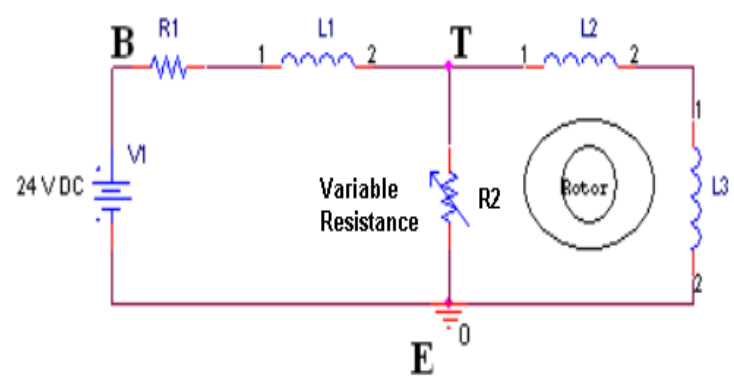

(b)

Fig 2: (a) Gauge to be tested (b) Electrical equivalent circuit of gauge
Table 1.Temperature Vs electrical parameters of gauge

\begin{tabular}{|c|c|c|c|}
\hline $\begin{array}{c}\text { Serial } \\
\text { No. }\end{array}$ & $\begin{array}{c}\text { Standard } \\
\text { Temperature } \\
\text { Levels in }{ }^{\circ} \mathbf{C}\end{array}$ & $\begin{array}{c}\text { Resistance } \\
\text { Value } \\
\text { (in } \mathbf{\Omega} \text { ohms) }\end{array}$ & $\begin{array}{c}\text { Tolerance } \\
\mathbf{\Omega}\end{array}$ \\
\hline 1 & 40 & 500 & 1 \\
\hline 2 & 60 & 238 & 1 \\
\hline 3 & 80 & 120 & 1 \\
\hline 4 & 100 & 66 & 1 \\
\hline 5 & 110 & 50 & 1 \\
\hline 6 & 120 & 38 & 1 \\
\hline
\end{tabular}

\subsection{The art-map of Non-Invasive Testing and Calibration System (NITCS)}

The art-map of non-invasive testing and calibration of temperature gauge is shown in Figure 3. It includes three modules viz: hardware, software and image acquisition. The hardware module consists of interfacing circuits, relays, and various displays and indicators. The software module consists of programs for image acquisition, processing, decision making, and display of results and image acquisition module consists of web camera, illumination, and gauge fixture alignment arrangements. 


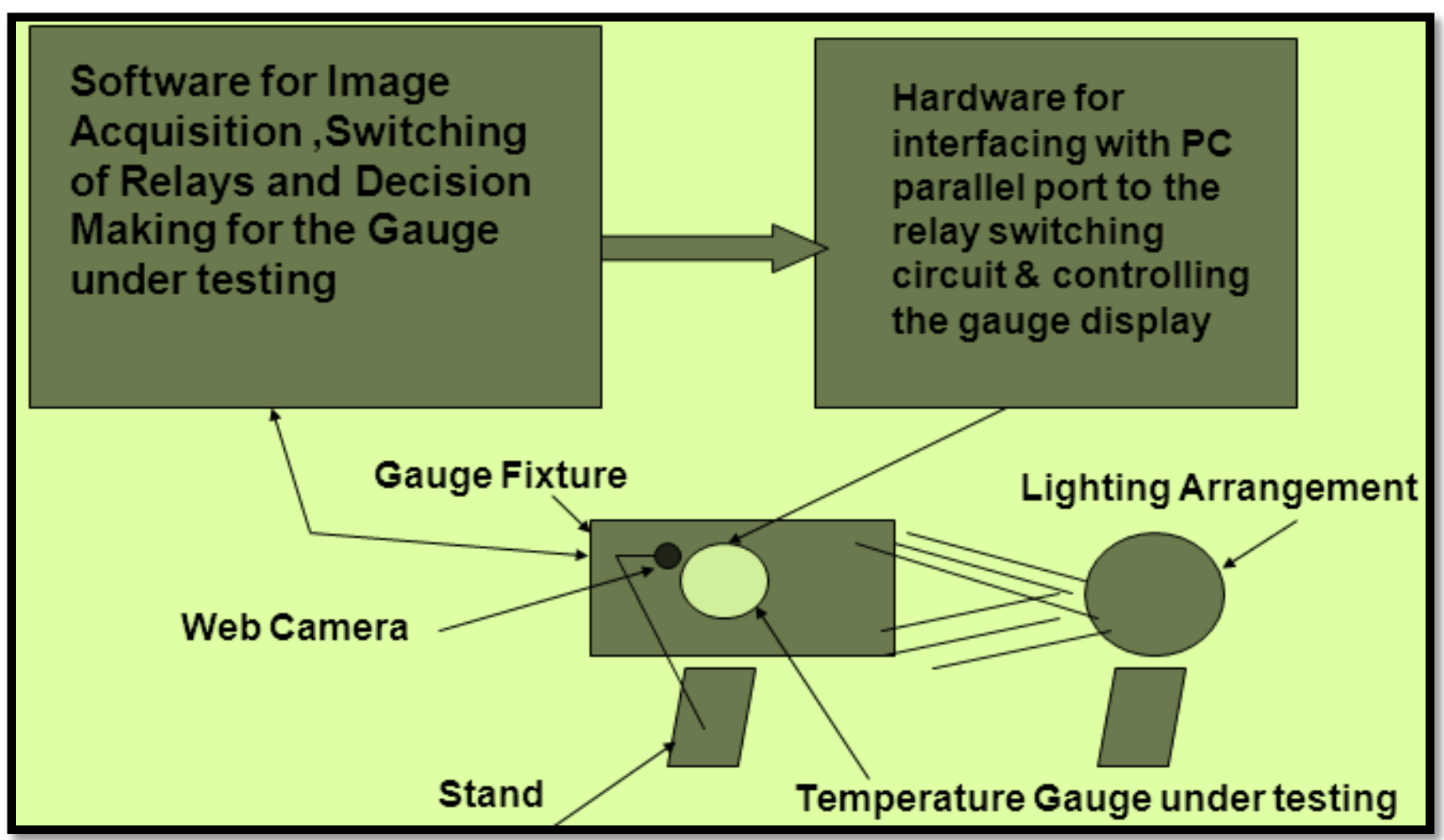

Fig 3: Art-map of non-invasive testing and calibration of temperature gauge model

\subsection{Image Acquisition}

The most important aspects of visual inspection system are image acquisition, because the quality of image sturdily influences the reliability of the system. The quality of captured image depends upon illumination, resolution of camera, reflectance [14] of object under test, angle of camera, and distance of camera from object. A smart optical sensing system reduces noise and blurring of image and hence fastens the inspection system. In this application web camera is used to capture the images in a sequence.

\subsection{Segmentation}

The threshold based segmentation technique is used to detect the pointer's image from the captured image [16]-[19]. The region of interest (ROI) selection algorithm is same as proposed by [18]. Figure 4(a) represents the RGB image in the selected ROI and Figure 4 (b) represents the segmented black \& white image of the pointer.

\subsection{Image Feature Calculation and Matching}

The features of segmented black and white image are calculated using the algorithm proposed by [18]. In this, geometrical and statistical feature of segmented image is calculated and matched using principal component analysis (PCA). If all the image features of segmented black and white image are same as the image features of that location in the gauge then the indicated value is recognized and accept (OK) signal is generated otherwise reject(NOT OK) signal is generated[20]-[23].

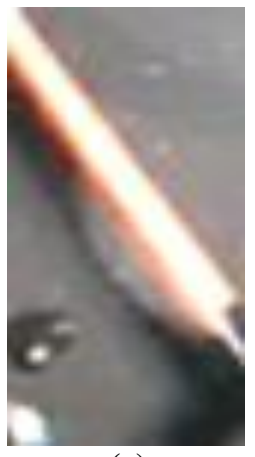

(a)

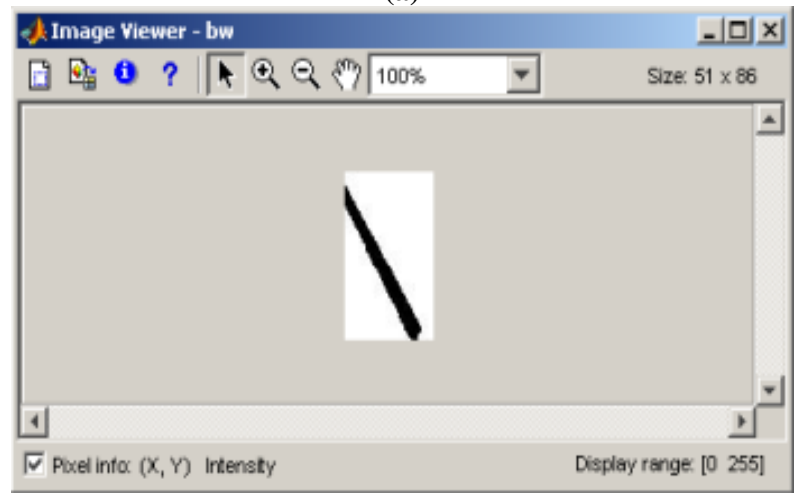

(b)

Fig 4: (a) Image in ROI (b) Segmented black \& white image of pointer 


\section{IMPLEMENTATION}

The experimental setup of NITCS is shown in Figure 5. The flow chart of NITCS is given in Figure 6. The proposed algorithm is implemented using MATLAB program. The graphical user interface (GUI) is also developed using MAT LAB to make the NITCS user friendly as shown in Figure 7. Figure 7(a) represents the main window while Figure 7(b) represents the setting window to set various parameters. All simulation is done using Core 2 Duo processor T5670 @ $1.80 \mathrm{GHz}, 1 \mathrm{~GB}$ RAM.

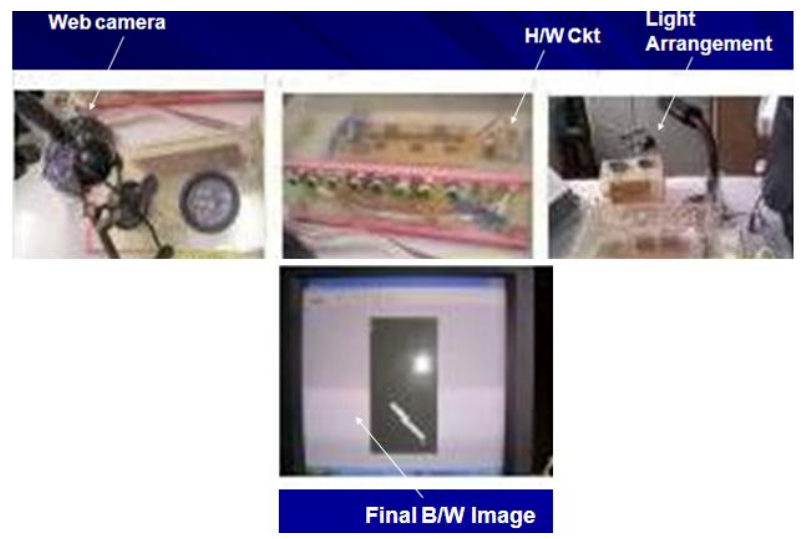

Fig 5: Experimental Setup of NITCS

\section{RESULTS}

The NITCS implemented successfully and results are shown in the Figure 8 and 9. The gauge under test is checked for all steps of temperature gauge dial. If image feature of is matched with the all corresponding values the ' $\mathrm{OK}$ ' i.e. accept is displayed as shown in Figure 8 and if not matched then 'NOT OK' is displayed as shown in Figure 9. If one or all steps displayed 'NOT OK' the final result is concluded as "NOT OK' i.e. reject.

Table 1.Comparison of NITCS with the existing manual

\begin{tabular}{|l|l|l|l|}
\hline \multicolumn{5}{|c}{ S. No } & \multicolumn{1}{|c|}{$\begin{array}{c}\text { Comparison } \\
\text { Factors }\end{array}$} & $\begin{array}{c}\text { Manual } \\
\text { System }\end{array}$ & \multicolumn{1}{|c|}{ NITCS } \\
\hline 1. & Type of Operation & Invasive & \multicolumn{1}{|c|}{$\begin{array}{l}\text { Non } \\
\text { Invasive }\end{array}$} \\
\hline 2. & $\begin{array}{l}\text { No of gauge } \\
\text { inspected per hour }\end{array}$ & $40-45$ & $60-62$ \\
\hline 3. & $\begin{array}{l}\text { Testing efficiency } \\
\text { of the system }\end{array}$ & $72-78 \%$ & $95-100 \%$ \\
\hline 4. & Reliability & $65-70 \%$ & $99.7 \%$ \\
\hline 5. & Quality assurance & $82-85 \%$ & $99.9 \%$ \\
\hline 6. & Human factor & $70 \%$ & $5 \%$ \\
\hline 7. & Environment factor & $20-25 \%$ & $5-10 \%$ \\
\hline 8. & $\begin{array}{l}\text { Re payment of } \\
\text { installation cost }\end{array}$ & $20-25$ days & $5-10$ days \\
\hline 9. & Running cost & More & Negligible \\
\hline 10. & $\begin{array}{l}\text { Maintenance } \\
\text { Required }\end{array}$ & $\begin{array}{l}\text { Routinely } \\
\text { Required }\end{array}$ & $\begin{array}{l}\text { sporadically } \\
\text { Required }\end{array}$ \\
\hline 11. & $\begin{array}{l}\text { Flexibility in } \\
\text { adaptability of new } \\
\text { technology }\end{array}$ & $\begin{array}{l}\text { Whole } \\
\text { system } \\
\text { requires } \\
\text { modification }\end{array}$ & $\begin{array}{l}\text { Can be } \\
\text { modified } \\
\text { easily }\end{array}$ \\
\hline 12. & Operation & Complicated & Simple \\
\hline & & \multicolumn{2}{|l}{}
\end{tabular}

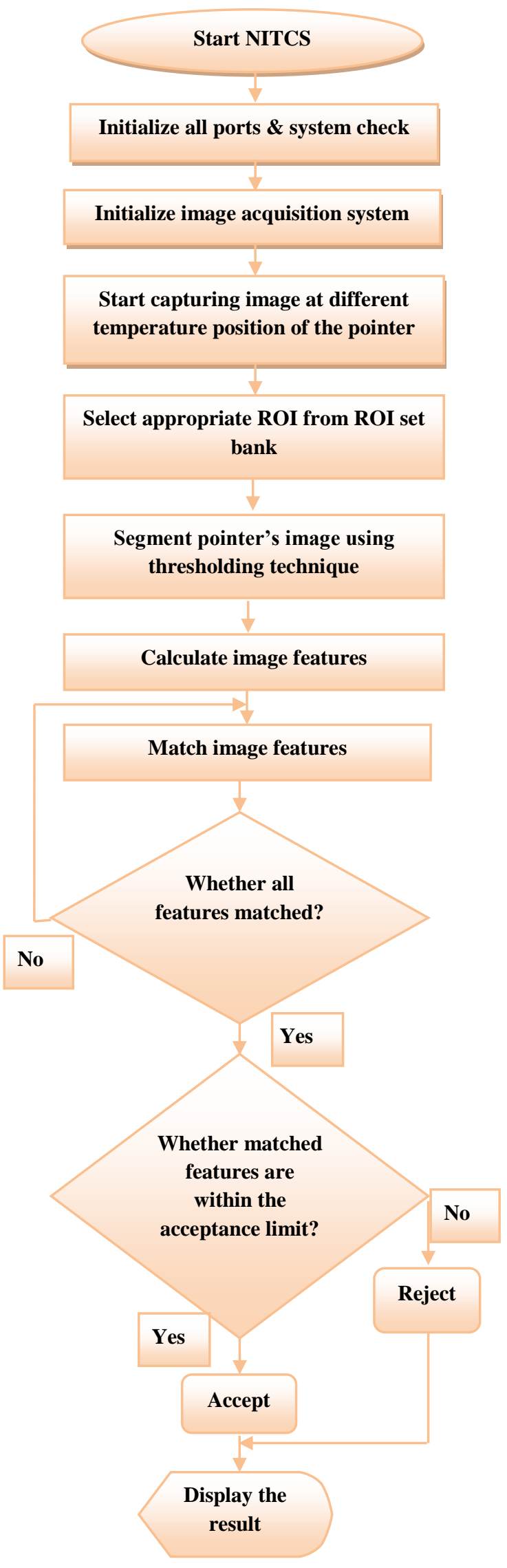

Fig 6: Functional flow chart of NITCS 


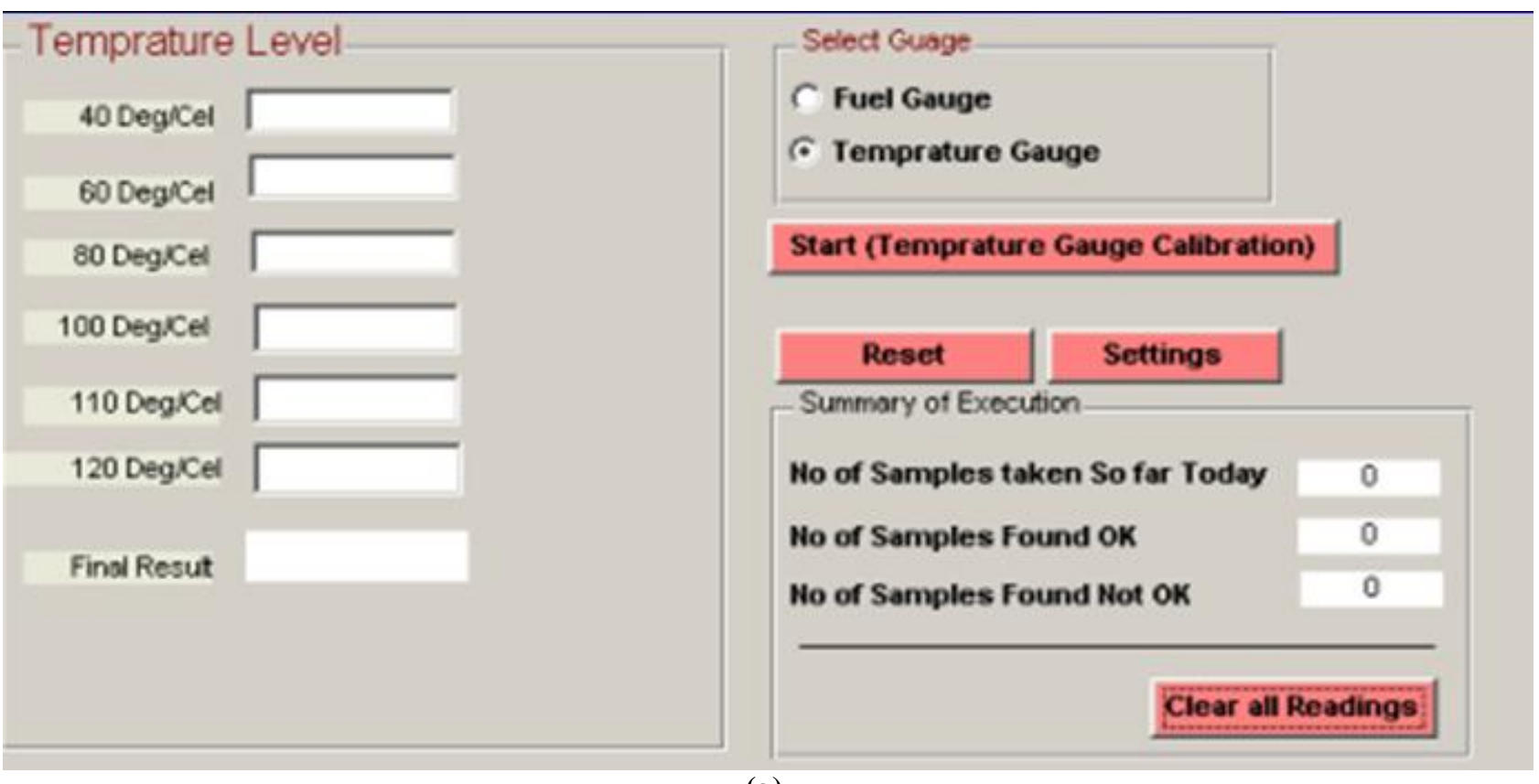

(a)

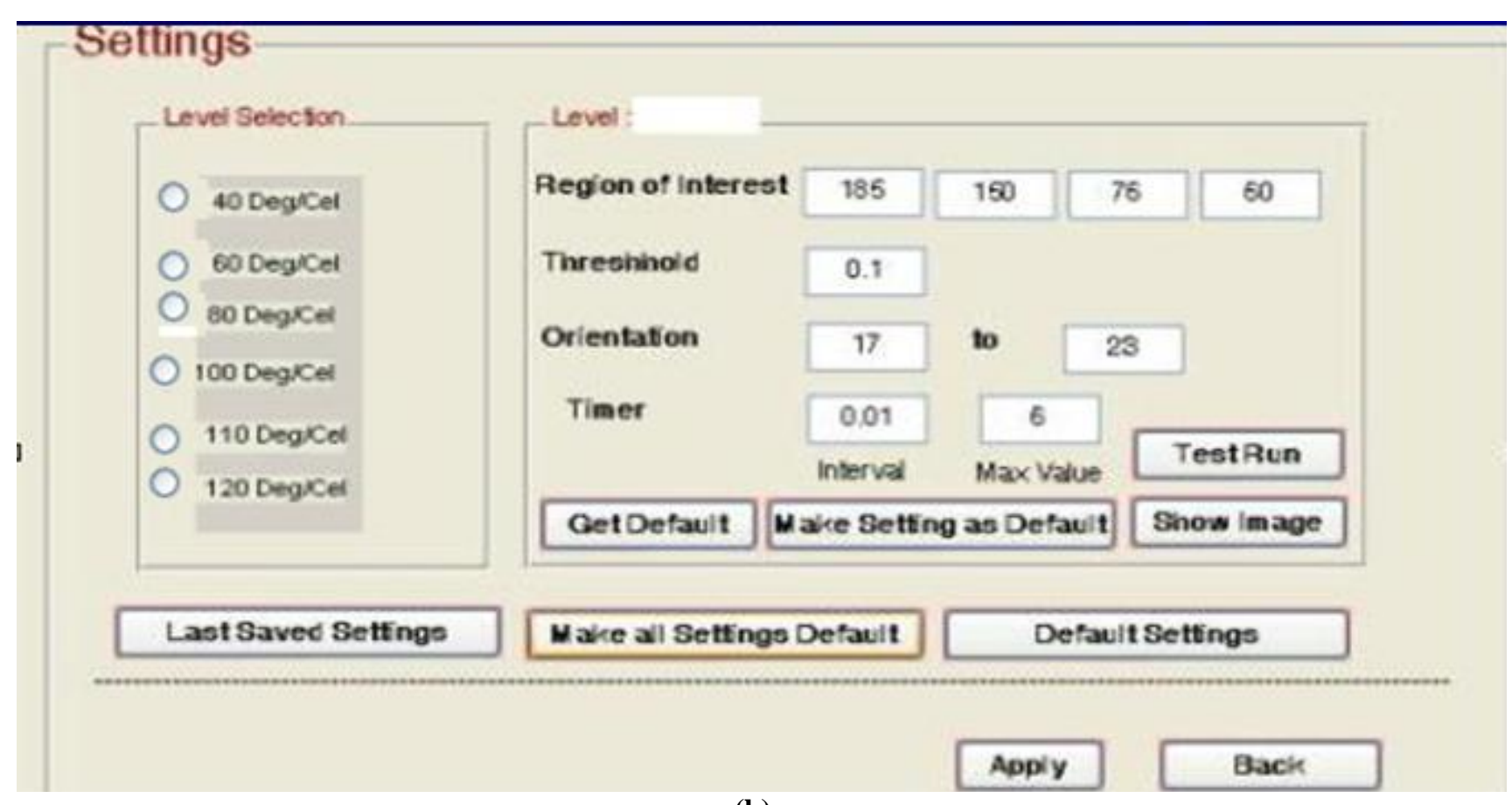

(b)

Fig 7: (a) Main window of NITCS (b) Settings window to set various parameters for processing 


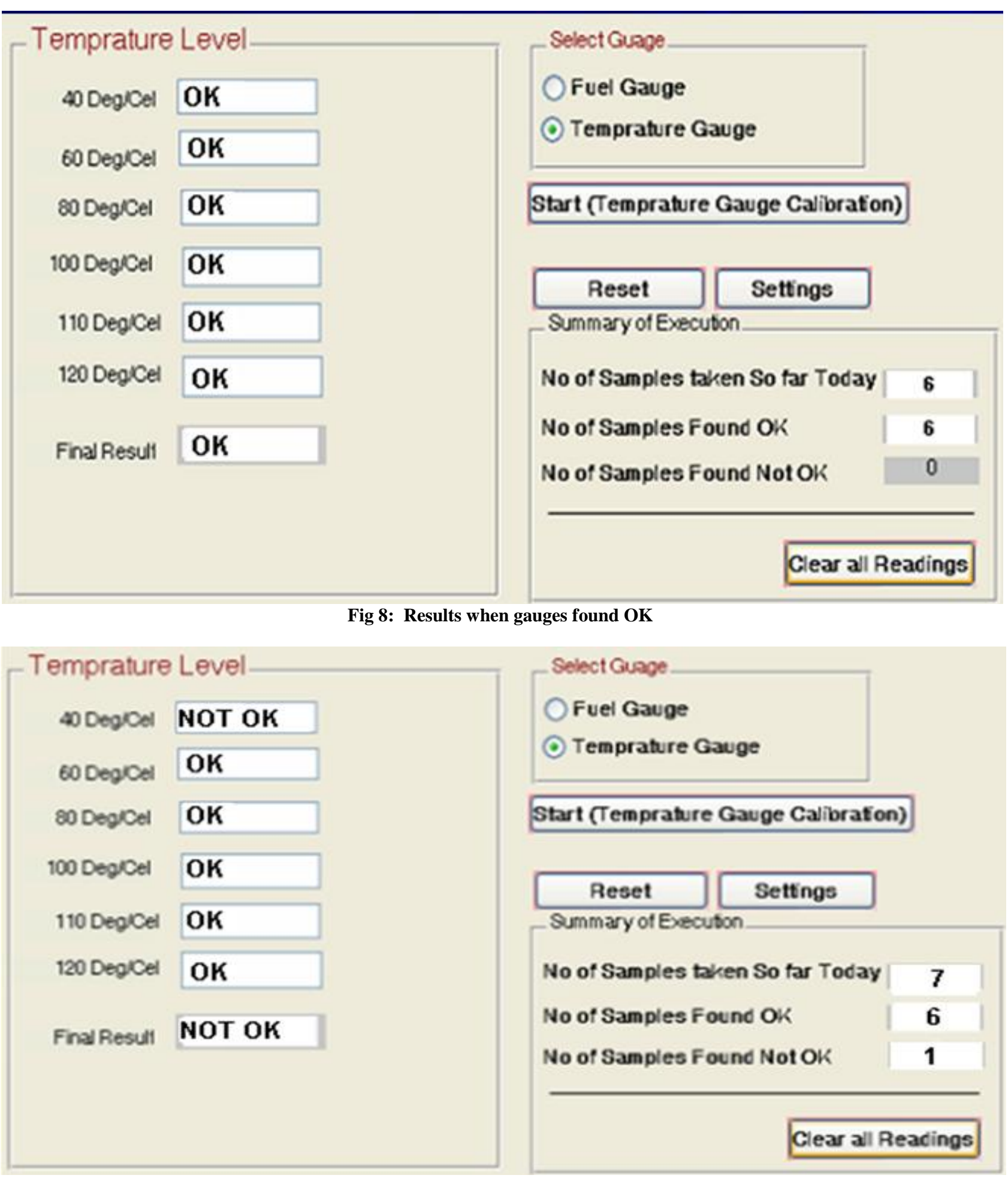

Fig 9: Result when gauge is NOT OK

\section{CONCLUSION}

The visual inspection system designed is completely user friendly, reliable, fast, and accurate. It reduces the cost of products up to a great extent. It enhances the quality assurance and hence improves the likeness of the product in the market. The proposed system had shown the consistent inspection performance. This concept of inspection system can be extended for the testing and calibration of other analog measuring instruments e.g. Wattmeter, ammeter, voltmeters, speedometers, and pressure gauge etc.

\section{REFERENCES}

[1] B. R. Suresh, , R. A. Fundakowski, T. S. Levitt, and J. E. Overland, "A Real-Time Automated Visual Inspection System for Hot Steel Slabs," IEEE Transactions on Pattern Analysis and Machine Intelligence, vol. 5, no. 6, pp. 563-572, June 1983. 
[2] F. Pernkopf and P. O'Leary, "Image acquisition techniques for automatic visual inspection of metallic surfaces," NDT\&E International, vol.36, no.8, pp.609617, Dec. 2003.

[3] A. Gonzalez, M. A. Garrido, D. F. Llorca, M. Gavilan, J. P. Fernandez, P. F. Alcantarilla, I. Parra, F. Herranz, L. M. Bergasa, M. A. Sotelo, and P. R. Toro, "Automatic traffic signs and panels inspection system using computer vision," IEEE Transactions on Intelligent Transportation Systems, vol. 12, no. 2, pp. 485-499, Jun. 2011.

[4] F. Marino, A. Distante, P. L. Mazzeo, and E. Stella, "A Real-Time Visual Inspection System for Railway Maintenance: Automatic Hexagonal-Headed Bolts Detection," IEEE Transactions on Systems, Man and Cybernetics - Part C: Applications and Reviews, vol. 37, no.3, pp. 418-428, May 2007.

[5] R. Sablatnig, "Increasing Flexibility for Automatic Visual Inspection: The General Analysis Graph," Machine Vision and Applications, vol. 12, no. 4, pp. 158-169, Dec. 2000.

[6] H. D. Lin, "Automated Defect Inspection of LightEmitting Diode Chips using Neural Network and Statistical Approaches," Expert Systems with Applications, vol. 36, no. 1, pp. 219-226, Jan. 2009.

[7] M. Shirvaikar, "Trends in automated visual inspection," Journal of Real-Time Image Processing, vol. 1, no.1, pp. 41-43, Oct. 2006.

[8] H. C. Garcia, J. R. Villalobos, R. Pang, and G. C. Runger, "A novel feature selection methodology for automated inspection systems," IEEE Transactions on Pattern Analysis and Machine Intelligence, vol. 31, no. 7, pp. 1338-1344, Jul. 2009.

[9] G. Ming and X. Yangsheng, "An Intelligent Online Monitoring and Diagnostic System for Manufacturing Automation,' IEEE Transactions on Automation Science and Engineering, vol. 5, no.1, pp. 127-139, Jan. 2008.

[10] I. Edinbarough, R. Balderas, and S. Bose, "A Vision and Robot Based On-Line Inspection Monitoring System for Electronic Manufacturing. Computers in Industry," Machine Vision Special Issue, vol. 56, no. 8-9, pp. 986996, Dec. 2005.

[11] G. L. Foresti, "Visual Inspection of Sea Bottom Structures by an Autonomous Underwater Vehicle," IEEE Transactions on Systems, Man, and CyberneticsPart B: Cybernetics, vol. 31, no. 5, pp. 691-705, Oct. 2001.

[12] D. Petkovic and E. B. Hinkle, "A Rule-Based System for Verifying Engineering Specifications in Industrial Visual Inspection Applications," IEEE Transactions on Pattern
Analysis and Machine Intelligence, vol. 9, no. 2, pp. 306311, Feb. 1987.

[13] Ž. Špiclin, M. Bukovec, F. Pernuš, and B. Likar, "Image Registration for Visual Inspection of Imprinted Pharmaceutical Tablets," Machine Vision and Applications, vol. 22, no. 1, pp. 197-206, Jan. 2011.

[14] X. Zhang, Y. Ding, L. Yan-yun, S. Ai-ye, and L. Rui-yu, "A Vision Inspection System for the Surface Defects of Strongly Reflected Metal Based on Multi-Class SVM," Expert Systems with Applications, vol. 38, no. 5, pp. 5930-5939, May 2011.

[15] H. Jia, F. Xi, A. Ghasempoor, and A. Dawoud, "A Tolerance Method for Industrial Image based Inspection," Intl. J. Advanced Manufacturing Technology, vol. 43, no. 11-12, pp. 1223-1234, Aug. 2009.

[16] N. R. Pal and S. K. Pal, "A review on image segmentation techniques," Pattern Recognition, vol. 26 , no. 9, pp. 1277-1294, Sep. 1993

[17] J. Melendez, M. A. Garcia, D. Puig, and M. Petrou, "Unsupervised texture-based image segmentation through pattern discovery", Computer Vision and Image Understanding, vol. 115, no. 8, pp. 1121-1133, Aug. 2011.

[18] H. Mobahi, S. R. Rao, A. Y. Yang, S. S. Sastry, and Y. Ma, "Segmentation of natural images by texture and boundary compression," International Journal of Computer Vision, vol. 95,no. 1, pp. 86-98, Oct. 2011.

[19] Z A Jaffery and A. K. Dubey, "Architecture of noninvasive real time visual monitoring system for dial type measuring instrument," IEEE Sensors Journal, vol.13, no. 4, pp. 1236-1244, Apr. 2013.

[20] K. W. Ko and H. S. Cho, "Solder Joints Inspection using a Neural Network and Fuzzy Rule-Based Classification Method," IEEE Transactions on Electronics Packaging Manufacturing, vol. 23, no. 2, pp.93-103, Apr. 2000.

[21] K. L. Chung, Z. W. Lin, S. T. Huang, Y. H. Huang, and H. Y. M. Liao, "New orientation-based elimination approach for accurate line-detection," Pattern Recognition Letters, vol. 31, no. 1, pp. 11-19, Jan. 2010.

[22] W. Krzanowski, "Between-groups comparison of principal components," Journal of the American Statistical Association, vol. 74, no. 367, pp. 703-707, Sep., 1979.

[23] K. Yang, and C. Shahabi, "A PCA-based similarity measure for multivariate time series," in Proc. 2nd ACM Int. Workshop on Multimedia Databases, Washington, 2004, pp. 65-74. 